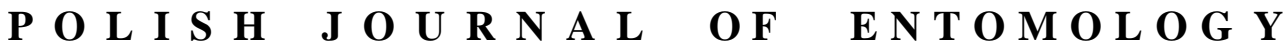

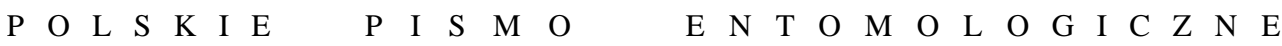

VOL. 85: 409-417

Lublin

31 December 2016

DOI: $10.1515 /$ pjen-2016-0025

\section{Susceptibility of hornbeam and Scots pine woods to destruction by the subterranean termite Reticulitermes lucifugus RosSI, 1792 (Blattodea: Isoptera)}

\author{
ADAM KRAJEWSKI ${ }^{*}$, PIOTR WITOMSKI, SZYMON KOTARBIŃSKI \\ Department of Wood Sciences and Wood Protection, University of Life Sciences - Szkoła \\ Główna Gospodarstwa Wiejskiego w Warszawie, ul. Nowoursynowska 159, \\ 02-787 Warszawa, Poland
}

\begin{abstract}
The article presents the results of tests of the degree of damage to Scots pine (Pinus sylvestris) and hornbeam (Carpinus betulus) woods by the termite Reticulitermes lucifugus. Both wood species are classified as "susceptible to destruction by termites" in the EN 350-2:2000 standard. The procedures described in the ASTM D 3345-08 standard (2009) were applied in the experiments. During laboratory coercion tests, wood samples from these two species were damaged to a degree between light attack and moderate attack with penetration. Recent Scots pine sapwood was damaged to a heavy degree. The results can be associated with the much higher density of hornbeam wood as compared to Scots pine sapwood. The mortality rate of the termites in the test containers with both wood species was similar and low, no greater than $10 \%$. In the light of the results, the classification of the susceptibility of native wood species to termite feeding, as stated in the EN 350-2:2000 standard, appears to be oversimplified.
\end{abstract}

KEY WORDS: Reticulitermes lucifugus, European subterranean termites, termite feeding, wood degradation

\section{INTRODUCTION}

The natural resistance of various wood species from Africa, Asia and South America to termite feeding has been of great interest for a long time. Several species are known, whose heartwood is relatively resistant to termite feeding. The impact on termites of a number of

\footnotetext{
*Corresponding author: adam_krajewski@sggw.pl
} 
chemical compounds contained in the heartwood of those trees (BECKER \& PETROWITZ 1971, BECKER et al. 1972, NAKAYAMA et al. 2001), as well as in filtrates obtained during the production of fuel from biomass (KARTAL et al. 2004), was examined a fairly long time ago. In recent years, research has focused on the natural resistance of various wood species from Alaska, of economic significance in the USA (GRACE \& YAMAMOTO 1994), as well as some American wood species used in the production of panelling (KARD et al. 2007). The natural resistance of various wood species provided by alternative forestry in Hawaii (GRACE et al. 1996) and of species significant to the natural environment in several parts of Africa (NCuBE et al. 2012) and Asia (Shanbhag \& Sundararaj 2013) has also been assessed.

The natural resistance of various European tree species to termite attack also aroused interest many years ago (SCHULZE-DEWITZ 1958). Nowadays, it is accepted that all European tree species of economic significance require additional chemical protection from termites (UNGER 1978): the EN 350-2:2000 standard describes all species except oak as "susceptible to destruction by termites". Such a classification seems to us to be an oversimplification, sometimes uncritically accepted as a dogma that requires no further clarification. Some different features of native woods, such as density and hardness, seem to suggest that the category of woods "susceptible to destruction by termites" contains species that can be damaged to a different degree in a given period of time, and hence at different rates. The significance of the density and hardness of a wood to its natural resistance is highlighted in the literature, as is the importance of the lignin and phenol compounds it contains (SHANBHA $\&$ SUNDARARA 2013). For this reason, we undertook research into the destruction of hornbeam (Carpinus betulus L.) wood, whose heartwood contains neither toxic or repellent compounds, and of Scots pine (Pinus sylvestris L.) wood, by Reticulitermes lucifugus, the most widespread species of soil termite in Europe (DOMINIK \& STARZYK 2004). The EN 350-2:2000 standard classifies both these species as woods susceptible to destruction by termites.

\section{MATERIALS AND METHODS}

The experiments were conducted in accordance with the ASTM procedure (2009). Scots pine sapwood and hornbeam sapwood was used to produce seasoned samples ( 25.4 x 25.4 x $6.4 \mathrm{~mm}$ ) with a $7 \% \pm 1 \%$ moisture content. The woods were taken from a group of blocks from three different trees. For each species, 5 samples were chosen at random.

In accordance with the ASTM (2009) recommendations, each sample was placed separately on the bottom of a test container (a $450 \mathrm{ml}$ glass vessel) and covered with 200 $\mathrm{g}$ of white sand previously screened, washed and heat-sterilized. The saturation point of the sand was established empirically. The amount of water used to moisten the sand in the test 
container was then reduced by $7 \%$ of the saturation point of the sand. The only deviation from the ASTM (2009) procedure was the fact that benzalkonium chloride solution was not used as antiseptic.

The biological experiments were conducted in a coercion test, in accordance with the above mentioned standard, on the termite Reticulitermes lucifugus Rossi, 1792. Reticulitermes lucifugus termites $(1 \pm 0.05 \mathrm{~g})$ were placed in each test container. Pseudergates made up $90 \%$ of all the individuals in each container. The containers with termites and wood samples were stored in an incubator at a temperature of $27^{\circ} \mathrm{C}$ for 4 weeks. The moisture level of the sand was checked weekly and topped up if necessary.

The ASTM procedure (2009) provides the following classification of termite mortality rate: low $(0-33 \%)$, average (34-66\%), high (67-99\%), complete $(100 \%)$. This is based on visual evaluation, not on calculations relating to the groups of insects tested.

The degree of damage to the samples, decisive for assessing the resistance or susceptibility of the wood to destruction by termites, was classified visually, based on the visual rating system and photographs given in the ASTM guidelines (2009): 10 - sound, surface nibbles permitted, 9 - light attack, 7 - moderate attack, penetration, 4 - heavy, 0 - failure. In ambiguous cases, an intermediate index was used. Average degrees of damage to the wood were calculated for each variant of the experiment. The significance of the difference between the average results obtained was checked statistically. Chebyshev's inequality was used to evaluate the significance of the average degree of damage in each variant of the experiment. If the absolute value of the difference between the arithmetic average values of the degree of damage to both wood species was greater than or equal to three times the standard error of the difference, i.e.

$$
\left|\overline{x_{1}}-\overline{x_{2}}\right| \geq 3 \cdot \varepsilon\left(\overline{x_{1}}-\overline{x_{2}}\right),
$$

then the difference between the average values taken to be statistically significant. Otherwise, it was regarded as accidental.

\section{RESULTS}

The results of the experiment, including the degree of damage to the wood samples and the mortality rate in each replicate of the given variant of the experiment, are presented in Table 1.

Given that the difference in the average values of damage to both wood samples is 6.4, and triple the value of the standard error is 3.12 , the difference was evaluated as statistically significant. 
Table 1. The degree of damage to samples of hornbeam and Scots pine wood and termite mortality (m) after a 4 week experiment. A - wood species and number of samples, $\mathrm{B}$ - degree of damage to wood samples, C - Average degree of damage to wood samples, D - estimated mortality of termites, E - average estimated mortality of termites.

\begin{tabular}{|c|c|c|c|c|}
\hline A & B & B & D & $\mathbf{E}$ \\
\hline \multirow{5}{*}{ hornbeam } & $9 / 7=8$ & \multirow{5}{*}{8.0} & $\mathrm{~m}<10 \%$ & \multirow{5}{*}{$\mathrm{m}<10 \%$} \\
\hline & $9 / 7=8$ & & $\mathrm{~m}<10 \%$ & \\
\hline & $9 / 7=8$ & & $\mathrm{~m}<10 \%$ & \\
\hline & $9 / 7=8$ & & $\mathrm{~m}<10 \%$ & \\
\hline & $9 / 7=8$ & & $\mathrm{~m}<10 \%$ & \\
\hline \multirow{5}{*}{ Scots pine } & 0 & \multirow{5}{*}{1.6} & $\mathrm{~m}<10 \%$ & \multirow{5}{*}{$\mathrm{m}<10 \%$} \\
\hline & 4 & & $\mathrm{~m}<10 \%$ & \\
\hline & $0 / 4=2$ & & $\mathrm{~m}<10 \%$ & \\
\hline & 0 & & $\mathrm{~m}<10 \%$ & \\
\hline & $0 / 4=2$ & & $\mathrm{~m}<10 \%$ & \\
\hline
\end{tabular}

The termites fed intensively on the wood, gathering around the samples placed on the bottom of the containers and constructing a gradually expanding network of corridors in the substrate and galleries above. The mortality rate of the termites in the experiments was classified as "slight" (0-33\%). Because of this slight mortality rate of the termites, no greater than $10 \%$, and because of its approximate nature, statistical verification was not applied here. The typical conditions of the hornbeam wood and the termite colony during the experiment are shown in Figure 1 and 2.

\section{DISCUSSION}

The procedures included in the ASTM (2009) procedure, designed for examining the resistance of ligno-cellulolytic materials to destruction by termites, were applied in this experiment, as the procedures in the EN 117:2005 standard are intended for determining toxic values of wood preservatives against European termites (Reticulitermes sp.) in laboratory tests and assume the obligatory occurrence of toxic effects.

The average degree of damage to hornbeam wood samples was four times less than the corresponding figure for Scots pine sapwood samples, although EN 350-2 (2000) includes both species in the same class, described as being "susceptible to destruction by termites". The results may be influenced by the interaction of density and hardness of both wood species. It is considered that the higher the density, the smaller the degree of damage (Shanbhag \& Sundararaj 2013). According to WAgENFÜHR \& ScheIbleR (1989), the 


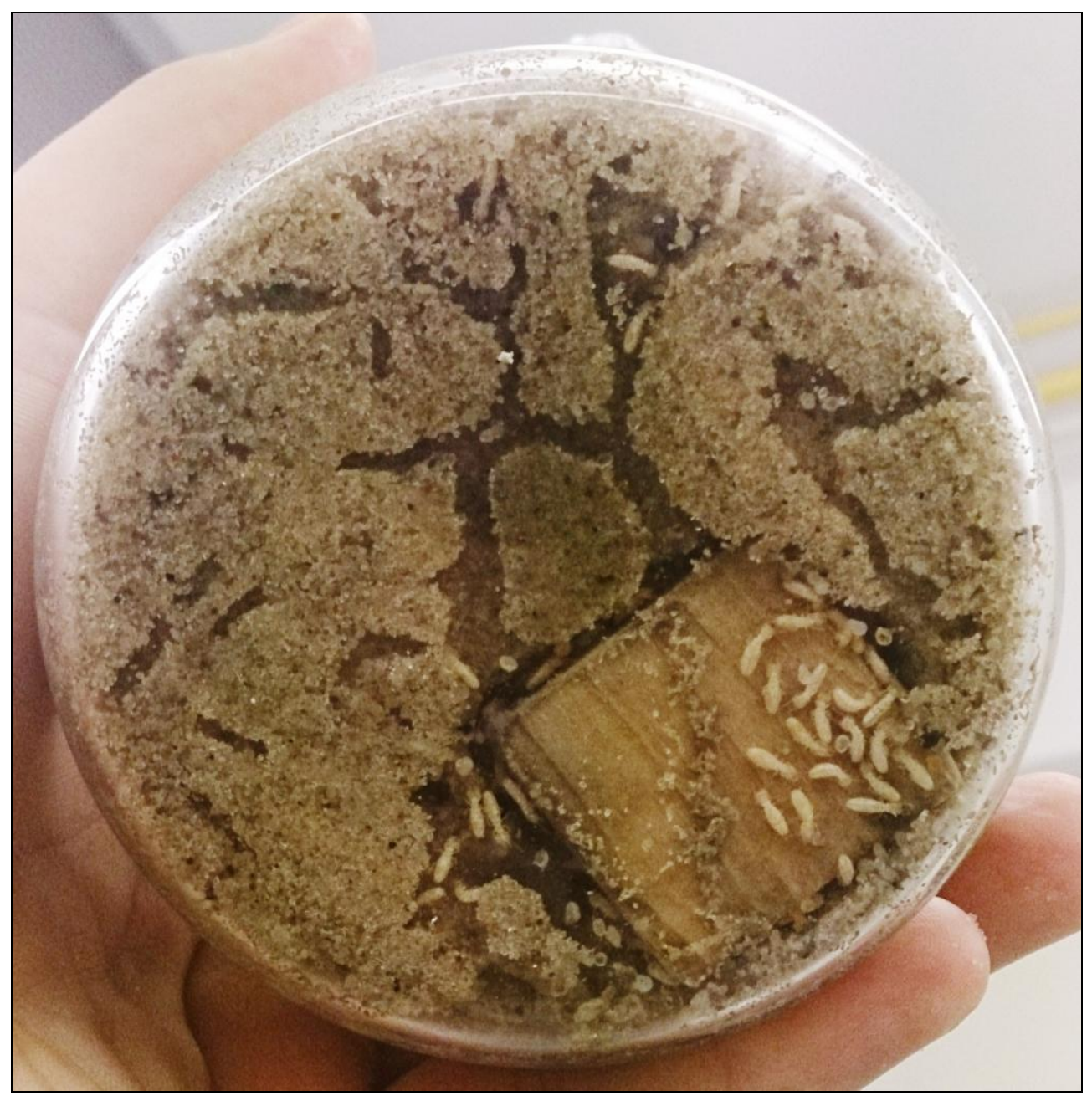

Fig. 1. The typical condition of hornbeam wood and termites' colony after 1 week of experiment.

density of hornbeam wood is between 0.50 and $0.82 \mathrm{~g} / \mathrm{cm}^{3}$ (average $0.79 \mathrm{~g} / \mathrm{cm}^{3}$ ), while that of Scots pine wood is between 0.30 and $0.86 \mathrm{~g} / \mathrm{cm}^{3}$ (average $0.49 \mathrm{~g} / \mathrm{cm}^{3}$ ). The densities of the wood samples used in the experiment did not differ from those values: $0.75 \mathrm{~g} / \mathrm{cm}^{3}$ for hornbeam and $0.46 \mathrm{~g} / \mathrm{cm}^{3}$ for Scots pine sapwood. Assuming that equally numerous groups of termites, during the same time and under the same temperature, moisture and soil conditions, are forced to ingest the same amount of food, the mass loss of hornbeam wood 


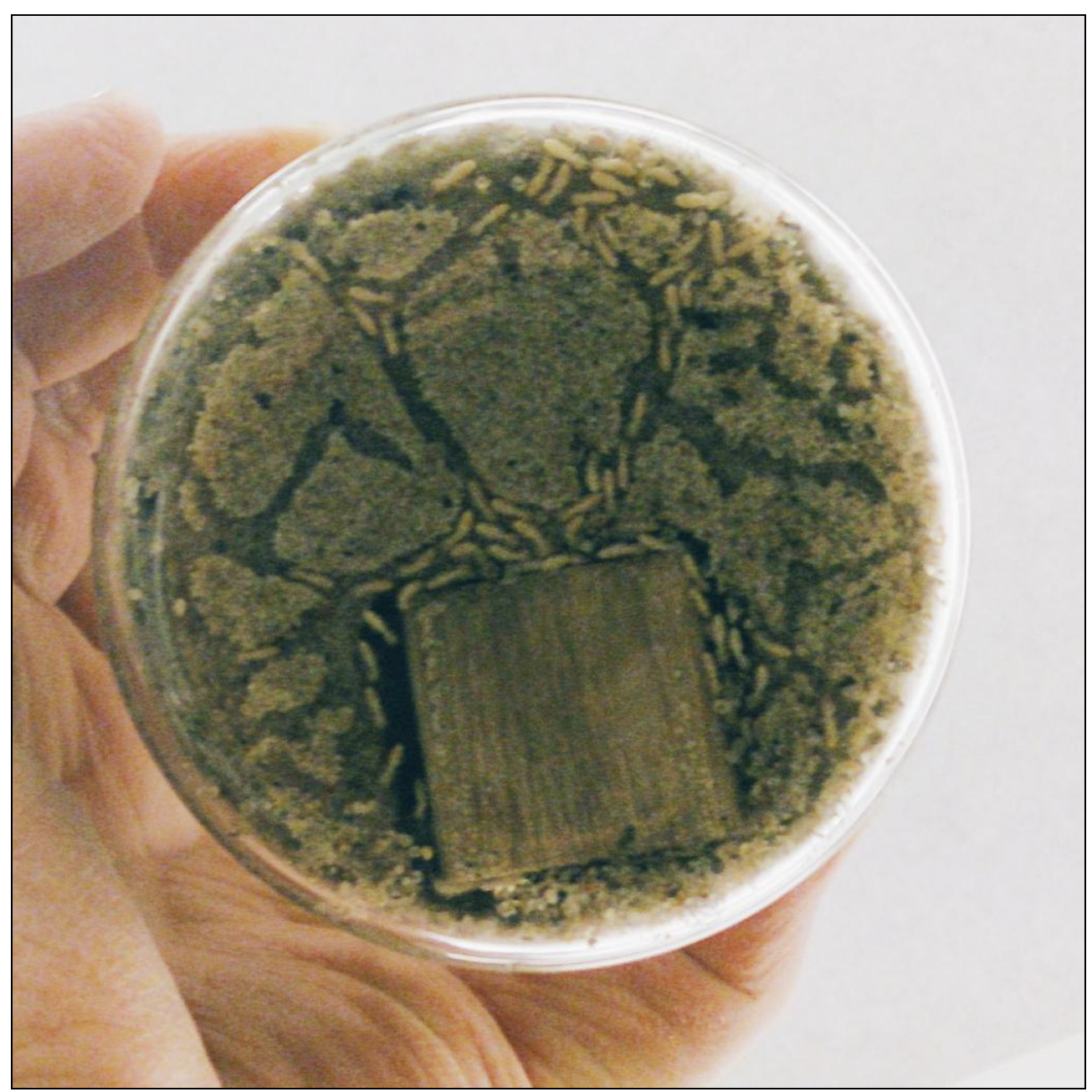

Fig. 2. The typical condition of hornbeam wood and termites' colony after 4 weeks of experiment.

should theoretically be $40 \%$ lower than the mass loss of Scots pine sapwood. Moreover, assuming that termites can efficiently digest only cellulose and hemicellulose, leaving lignin undigested (BECKER 1963, KÖNIG et al. 2013), an additional factor influencing the degree of damage to wood is the polysaccharide content of the wood. This, however, was not established for the wood samples in these laboratory tests. Nonetheless, according to the values given in the literature (WAGENFÜHR \& SCHEIBLER 1989), their total amount can be assumed to be similar for both wood species. 
The four-times greater degree of damage to Scots pine sapwood may also be due to its being softer than hornbeam. The hardness of materials as a factor able to reduce the extent of damage is also referred to in the literature (DOMINIK \& STARZYK 2004). Deep corridors are more easily gnawed in softer wood, so the insects do not need to consume all the wood. Soil termites are genetically programmed to inhabit the wood in which they are capable of gnawing their corridors.

The possible mortality of pseudergates must also have an impact on the extent of damage to the wood. The ASTM (2009) procedure provides a very wide range of values (between 0 and 33\%) for the lowest class of mortality rate, described as "low". Whereas dead soil termites are very conspicuous on the soil surface, those remaining in the tunnels in the substrate are very difficult to find. The altered colour of dead termites is also unfavourable and makes it impossible to count them precisely. For these reasons, the EN 117 (2005) procedure assumes the test to be valid if the termite mortality rate of termites is $<50 \%$. This is relatively easy to assess, especially as the standard defines groups of termites by their numbers, not by their mass, as described in ASTM (2009).

In our examination of both wood species the situation was actually rather convenient in this respect, as there were only a very few dead termites - estimated at $<10 \%$ of the total number of termites in the groups used in the experiment. Neither of the wood species tested contained any toxic substances or repellents, such as are found in many other wood species tested for destruction by termites (GRACE \& YAMAMOTO 1994, GRACE et al. 1996, KARD et al. 2007). As there were no toxic substances in our wood samples, the termite mortality rate in the tests was low. Only the greater hardness of the hornbeam wood, as compared to the Scots pine wood, could have caused there termites some difficulty.

Lastly, it must be emphasized that the degree of damage to wood by termites, as stated in ASTM (2009), gives information on losses to the wood caused by termite feeding but does not provide a precise conversion factor into mass loss. A four-times lower average index of the degree of damage does not necessarily mean a four-times lower mass loss of the wood samples. Nevertheless, the average indicators of the degree of damage to both wood species is a good illustration of the extent of destruction of the samples. The classification of destruction of impregnated wood, included in EN 117 (2005), is also based on indicators of the degree of damage (from 0 to 4 ).

\section{CONCLUSIONS}

The density of wood has a significant influence on feeding Reticulitermes lucifugus. The classification of both hornbeam wood and Scots pine wood as "susceptible to destruction by termites" included in EN 350-2 (2000), though undoubtedly true, greatly 
oversimplifies the assessment of biodegradation phenomena in this regard. Because of its much higher density, hornbeam wood is damaged to a much lower degree than Scots pine wood during the same period of time. The feeding of termites degrading hornbeam wood is thus much slower than the corresponding degradation of Scots pine sapwood.

\section{REFERENCES}

BECKER G. 1963. Holzbestandteile und Hausbock-Entwicklung. Holz als Roh- und Werkstoff 21(8): $285-289$.

BeCKER G., LenZ M., DietZ S. 1972. Unterschiede im Verhalten und Giftempfindlichkeit verschiedener Termiten-Arten gegenüber einigen Kernstoffen. Zeitschrift für angewandte Entomologie 71(1-4): 201-214.

BeCKER G., Petrowitz H.-J. 1971. Über die Ursache der abschreckenden Wirkung von Kiefernholz auf Termiten. Zeitschrift für angewandte Entomologie 68(1-4): 180-186.

DOMinik J., STARZYK J.R. 2004. Insects damaging wood. PWRiL, Warszawa. [in Polish]

Grace J.K., Yamamoto R.T. 1994. Natural resistance of Alaska-cedar, redwood, and teak to Formosan subterranean termites. Forest Products Journal 44(3): 41-46.

Grace J.K., Ewart D.M., Tome Carrie H.M. 1996. Termite resistance of wood species grown in Hawaii. Forest Products Journal 46(10): 57-60.

Kard B., Hiziroglu S., Payton M. E. 2007. Resistance of eastern red cedar panels to damage by subterranean termites (Isoptera: Rhinotermitidae). Forest Products Journal 57(11): 74-79.

Kartal S.N., Imamura Y., Tsuchiya F., Ohsato K. 2004. Preliminary evaluation of fungicidal and termicidal activities of filtrates from biomass slurry fuel production. Bioresource Technology 95(1): 41-47.

KÖNIG H., Li L., FrÖHLICH J. 2013. The cellulolytic system of the termite gut. Applied Microbiology and Biotechnology 97(18): 7943-7962.

Krajewski A., Lisiecka E., DrożdżeK M., Witomski P., Wójcik A. 2015. The susceptibility of Neolithic waterlogged beech wood (Fagus sylvatica L.) to destruction by Reticulitermes lucifugus Rossi. Drewno. Prace naukowe. Doniesienia. Komunikaty 58(195): 59-68.

NAKAYAma F.S., Vinyard S.H., Chow P., Bajwa D.S., YoungQuist J.A., Muehl J.H., KrZYsik A.M. 2001. Guayule as a wood preservative. Industrial Crops and Products 14(2): 105-111.

Ncube E., Chungu D., Kamden D.P., Musawa K. 2012. Use of a short field test to evaluate termite resistance of Eucalyptus grandis and Bobgunnia madagascarensis in a tropical environment. BioResurces 7(3): 4098-4108.

Peterson C.J., Gerhard P.D., WAGNER T.L. 2008: Charring does not affect wood infestation by subterranean termites. Entomologia Experimentalis et Applicata 126(1): 78-84.

SCHULTZE-Dewitz G. 1958. Vergleichende Untersuchungen der natürlichen Fraßresistenz einiger einheimischer Kernholzarten unter Verwendung von Calotermes flavicollis FABR. und Reticulitermes lucifugus Rossi als Versuchstiere. Holz als Roh- und Werkstoff 7(16): 248-251. 
Shanbhag R.R., Sundararaj R. 2013. Physical and Chemical Properties of Some Imported Woods and their Degradation by Termites. Journal of Insect Science 13: 63.

UNGER W. 1978. Termitenschäden an Materialen und Möglichkeit ihrer Verhütung. Holztechnologie 4(10): 195-199.

WAGENFÜHR R., ScheibleR C. 1989. Holzatlas, 3. Auflage. VEB Fachbuchverlag, Leipzig.

\section{LIST OF STANDARDS}

ASTM D 3345-08 2009. Standard Test Method for Laboratory Evaluation of Wood and other Cellulosic Materials for Resistance to Termites. ASTM D 2245-08. 3 pp.

EN 117 2005. Wood preservatives. Determination of toxic values against Reticulitermes species (European termites) (laboratory method).

EN 350 -2 2000. Durability of wood and wood-based products - Natural durability of solid wood PART 2: Guide to natural durability and treatability of selected wood species of importance in Europe.

Received: 22 April 2016

Accepted: 15 June 2016 